\title{
Assessment of Preventive Measures Among Health Care Workers Regarding Nosocomial Infections in Kut City Hospitals
}

\author{
Qasim Abbas Khyoosh Al.Eqabi ${ }^{1}$, Shrouk Abdulrazak Hassan Al.Ibraheem ${ }^{2}$, Tareq Mahdi AL.Qassab ${ }^{3}$ \\ \{ qasim.abbas.kh@gmail.com¹, shrouk.albraheem@stu.edu.iq ${ }^{2}$, tareq.mahdi@mtu.edu.iq $\left.{ }^{3}\right\}$ \\ Community health Techniques/ Al-Furat Al-Awsat Technical \\ University-Iraq ${ }^{1}$ \\ Medical laboratories techniques/ Southern Technical University- \\ Iraq $^{2}$ \\ Community Health Technology/ Middle Technical University-Iraq ${ }^{3}$
}

\begin{abstract}
The aim is to assess the preventive measures of HCWs and determine the relationship between preventive measures and the demographic characteristics of HCWs. Methods: Cross-sectional study conducted among $500 \mathrm{HCWs}$ in Wasit governorate hospitals. This sample was distributed throughout four hospitals include, AL-Zahra, ALKarama teaching hospitals, AL-Kut gynecology hospital, and Martyr Fairouz general hospital, for the period of October 15th, 2020, to May 15th, 2021. Through self-report and questionnaires, data were collected and analysed through descriptive and inferential statistics. Results: Findings depict that majority of age groups among those who are 20-29 years old $63.2 \%, 50.2$ were male residence in urban areas, 36.2 were medical assistance, and hold a diploma, work less than 10 years and within adequate training. Finding reveals that the majority of $49.8 \%$ were poor preventive measures. There was a significant relationship between preventive measures with age, and years of experience of HCWs. Conclusion: Poor preventive measures towards NIs, more years of experience, and more training the staff help raising professionals' health workers.
\end{abstract}

Keywords: Health care workers (HCWs), Preventive measures, Nosocomial Infections (NIs).

\section{Introduction}

Health-care workers are the cornerstone of healthcare systems; a healthy and professional workforce is a must for a healthy community, and this is especially important in times of crisis like the COVID-19 pandemic ${ }^{[1]}$. Health care workers should also be well-informed about the disease and take precautions to protect themselves and the population as a whole ${ }^{[2]}$. It is the responsibility and duty of all healthcare workers to prevent healthcare-associated infections, professionals in infection control need evidence-based educational content to decrease HAIs ${ }^{[3]}$. Therefore, to achieve optimal prevention and control of HAI as a regulatory goal, most hospitals have recognized and reached written measurable standards for preventing this infection ${ }^{[4]}$. Hand cleaning, adequate personal protective equipment, aseptic procedures to prevent patient exposure to microbes, and the monitoring of sharps, blood spills, linen, and garbage to ensure a safe environment are all standard precautions ${ }^{[5]}$. According to the Centers for Disease Control and Prevention, universal precautions are a set of precautions designed to avoid pathogen transmission when providing health care ${ }^{[6]}$. Using personal safety barriers such as gloves can reduce exposure accidents to a great extent ${ }^{[7]}$. In addition to the use of face masks, goggles, 


\section{DOI 10.4108/eai.7-9-2021.2314879}


overhead caps, and gowns, washing hands after disposing of gloves, not returning needles, sanitary disposal of medical waste, sterilization of surgical tools ${ }^{[8]}$. Hand hygiene is a simple, easy-to-implement habit and an effective method that can help to reduce the risk of infection ${ }^{[9]}$. The most important intervention in infection prevention is still washing hands ${ }^{[10]}$.

Hand hygiene is measured by the World Health Organization's five moments of hand hygiene, which include washing hands before touching the patient, before clean/sterile operations, after exposure to the risk of body fluids, after touching the patient, and after touching the patient's area $^{[11]}$. Health workers should always wear personal protective equipment, such as gowns, gloves, goggles, face shields, surgical masks, cardiopulmonary resuscitation masks, head coverings, respirators, and shoe cover because they establish a physical barrier that protects health workers from meeting contaminated or contagious materials ${ }^{[12]}$, In addition to protect patients and visitors from threats to their health ${ }^{[13]}$. Therefore, this study amid to assess preventive measurements of HCWs; and determine the relationship between preventive measures and demographic characteristics of HCWs.

\section{Methodology}

A descriptive cross-sectional study through the use assessment approach and questionnaire items is conducted to explore preventive measures is conducted among 500 healthcare workers selected throughout the use of non-probability sampling approach at four hospitals in kut city divided as follows 135 from AL-Zahra teaching hospital, 125 from AL-Karama teaching hospital, 110 from AL-Kut gynecology obstetric and paediatrics hospital, and 130 from Martyr Fairouz general hospital, to explore preventive measures about nosocomial infections among health care workers. The study was conducted from October $15^{\text {th }} 2020$ to May $15^{\text {th }} 2021$. Data was collected using a questionnaire and self-report technique, A questionnaire was created through a related comprehensive review of the literature, which was used as a data collection tool that included socio-demographic characteristics; and preventive measures composed of (20) items. Data was collected using a questionnaire "self-administrative" health worker. The researcher introduced himself to the participants and explained the purpose of the study to get oral agreement. The questionnaire fills out an answer by the participants (health workers). "Through used SPSS-ver. 24 to analyse and evaluate the study data used descriptive analysis to describe the study variables: frequencies and percentages; and inferential statistic include Chisquare "test.

\section{Results and Discussion}

\subsection{Part I: Socio-Demographic Characteristics}

The results of the study appeared that 500 samples who participated in this study their age ranged from 20-29 years old and constituted $63.2 \%$ as a high percentage at mean + $\mathrm{Sd} .=30.18+8.620$, while the age $<20$ years composed the lowest percentage out a total of the study sample, as shown in table 1 . These results come due to the increasing number of graduates from medical institutes and colleges in Iraq and their enrolment in the direct job more than before. These findings agreed with the study conducted by Tripura deals with hospital-acquired infection knowledge. Findings depict most of the study participants were from 18 to 25 years age group $70.7 \%{ }^{[14]}$. 
The distribution of gender in this study composed $50.2 \%$ were male and $49.8 \%$ were female, due to the male more responses to participants in the study. findings come in the same line with a study conducted in Gondar and deals with health care workers regarding infection prevention. Their findings depict that most of the study participants were male, constituted $50.7 \%$ were male ${ }^{[15]}$.

The results that urban residents were predominant, it constituted $96.2 \%$ out a total number of the study population, as being the hospitals covered by the study are in urban areas so, the health care workers residents in those areas. These results agree with the findings of a study conducted in the Wasit governorate. Found that most of the study participants $94.7 \%$ of health workers in two hospitals were residing in an urban area ${ }^{[16]}$.

The results reveal the distribution of study sample according to specialty, findings depicts that most of the study participants were medical assistant, it constituted $36.2 \%$ out the total number. Science specialization was the lowest among the results. Being the specialist was considered the major proportion of staff in a health organization, due to the large number of institutions that graduate from such departments. While in a study that found the highest proportion of health workers in Al-Kut hospital 39.1\% were nurses compared to $36.8 \%$ of health workers in Al-Karamah teaching hospital were technicians ${ }^{[16]}$.

The results that diploma graduated were more than half of the study sample. It constituted $56.8 \%$ of the total number of the study population. While the high diploma is the lowest percentage. The presence of institutes in most of the governorates and the graduation of batches of morning and evening study in large numbers in addition to the presence of several departments and various specialties.

Some previous studies agreed with this result, Okwii, found diploma health care workers constituted $48.9 \%$ as a majority. In Middle East hospitals found that most respondents depict to have a diploma which indicates $63.6 \%{ }^{[17]}$.In regarding the years of experience, results indicate that $73.4 \%$ had less than 10 years as predominant findings. As is most of them find new appointments. Because of new hires and the exploitation of young energies among those with working experience $>5$ years were about 85 respondents $43.4 \%$ in a study conducted in Yemen and assessed the standard precautions and nosocomial infection ${ }^{[18]}$.

The results that most of the study participants work less than 8 hours daily, constituted $88.4 \%$ out the total number of the study population due to result indicates that the health workers work in the morning shift, as stated in the study cross-sectional study conducted in northwest Ethiopia deals with Knowledge, attitude, and practice of healthcare professionals regarding infection prevention at Gondar University referral hospital. Their findings depict that working hour among health care workers per day are 8 hours $63.8 \%{ }^{[15]}$.

Results indicate that laboratories workers were predominant among the study population, which composed $28.8 \%$ of the total number. Because of their large numbers and the diversity of their specialties. While in the study Okwii, stated that $30.7 \%$ of the respondents were from the medical ward, $26.1 \%$ were from paediatrics, $21.6 \%$ from surgery, and $21.6 \%$ from accident and emergency ${ }^{[19]}$. Distribution of the study sample according to the training course, most of them had one session of training and composed $32.2 \%$ out the total number. Participation in a training session in Iraq is diminished due to the political and economic limitations and this is controlled by the policy of the minister of health of Iraq. These results matched with a cross-sectional study conducted by Yazie et al., who found that more than half $55.3 \%$ of the study participants were untrained, is only $44.7 \%$ of them were taken training regarding infection prevention and safety in northwest Ethiopia ${ }^{[15]}$. 
Table 1. Descriptive statistics of demographic variables.

\begin{tabular}{|c|c|c|c|}
\hline Variables & Rating & $\mathrm{N}=500$ & $\%$ \\
\hline \multirow{5}{*}{ Age } & $<20$ years old & 5 & 1.0 \\
\hline & $20-29$ years old & 316 & 63.2 \\
\hline & $30-39$ years old & 121 & 24.2 \\
\hline & $40-49$ years old & 39 & 7.8 \\
\hline & 50 and older & 19 & 3.8 \\
\hline \multirow{2}{*}{ Gender } & Male & 251 & 50.2 \\
\hline & Female & 249 & 49.8 \\
\hline \multirow{2}{*}{ Residences } & Urban & 481 & 96.2 \\
\hline & Rural & 19 & 3.8 \\
\hline \multirow{5}{*}{ Specialty } & Physician & 52 & 10.4 \\
\hline & Nurse & 151 & 30.2 \\
\hline & Medical technologies & 96 & 19.2 \\
\hline & Medical assistance & 181 & 36.2 \\
\hline & Sciences & 20 & 4.0 \\
\hline \multirow{5}{*}{ Education attainmen } & Preparatory & 30 & 6.0 \\
\hline & Diploma & 284 & 56.8 \\
\hline & Bachelors & 156 & 31.2 \\
\hline & Higher diploma & 11 & 2.2 \\
\hline & Master and above & 19 & 3.8 \\
\hline \multirow{3}{*}{ Years of experience } & $<10$ years & 367 & 73.4 \\
\hline & $10-20$ years & 115 & 23.0 \\
\hline & 21-30 years & 18 & 3.6 \\
\hline \multirow{2}{*}{ Work hours } & $\leq 8$ hours & 442 & 88.4 \\
\hline & $>8$ hours & 58 & 11.6 \\
\hline \multirow{7}{*}{ Workplace } & Emergency department & 58 & 11.6 \\
\hline & Consulting department & 84 & 16.8 \\
\hline & Surgical wards & 45 & 9.0 \\
\hline & Medical wards & 53 & 10.6 \\
\hline & Maternity wards & 43 & 8.6 \\
\hline & Pediatric wards & 35 & 7.0 \\
\hline & Laboratories & 144 & 28.8 \\
\hline \multirow{4}{*}{ Training course } & No training & 146 & 29.2 \\
\hline & One session & 161 & 32.2 \\
\hline & Two sessions & 108 & 21.6 \\
\hline & More than two sessions & 85 & 17.0 \\
\hline
\end{tabular}

\subsection{Part II: Preventive Measures Towards Nosocomial Infections}

The findings presented the overall health care workers' preventive measures toward nosocomial infections in Wasit governorate hospitals. Finding reveals that the majority of $49.8 \%$ were poor preventive measures at the low level of mean, due to the lack of monitoring by authorities, in addition to the shortage of medical facilities, we find a great shortage of personal protective equipment in hospitals. On the other hand, most of the training courses are theoretical presentations without practical application, Fig.1. show the status. Our results are consistent with those of an Iranian study conducted in Yazd, the practice among health care staff was poor, 
the negative results were $49 \%$ from the total, due to staff deficiency failing health personnel to comply with medical instructions. Our results are consistent with those of an Iranian study conducted in Yazd, the practice among health care staff was poor, the negative results were $49 \%$ from the total, due to staff deficiency failing health personnel to comply with medical instructions ${ }^{[20]}$. Study in Yemen among healthcare workers to assess the preventive measures of nosocomial infections, their results show that over half $53.9 \%$ have poor practice and $46.1 \%$ of them had a good level practice. The poor practice returns to disparities in their education this result shows that there is a gap between the theoretical and practical aspects, which indicates that it is necessary to link between the theoretical and practical aspects about infection and its control $^{[21]}$. Also, findings concerning preventive measures for nosocomial infections, found that $33.3 \%$ have practiced while $66.7 \%$ do not practice preventive measures for nosocomial infection, because of the shortage in availability of medical facilities ${ }^{[22]}$.

At the University of Gondar comprehensive specialized hospital in northwest Ethiopia, most respondents have poor infection control practices $64 \%$ when it comes to HAI prevention. This lower result may be due to variations in the study sites' sanitary facilities and logistical requirements for HAI prevention activities. Other factors associated with the good practice were also not positively applied by $\mathrm{HCWs}$, indicating that equipment and materials are inaccessible ${ }^{[23]}$.

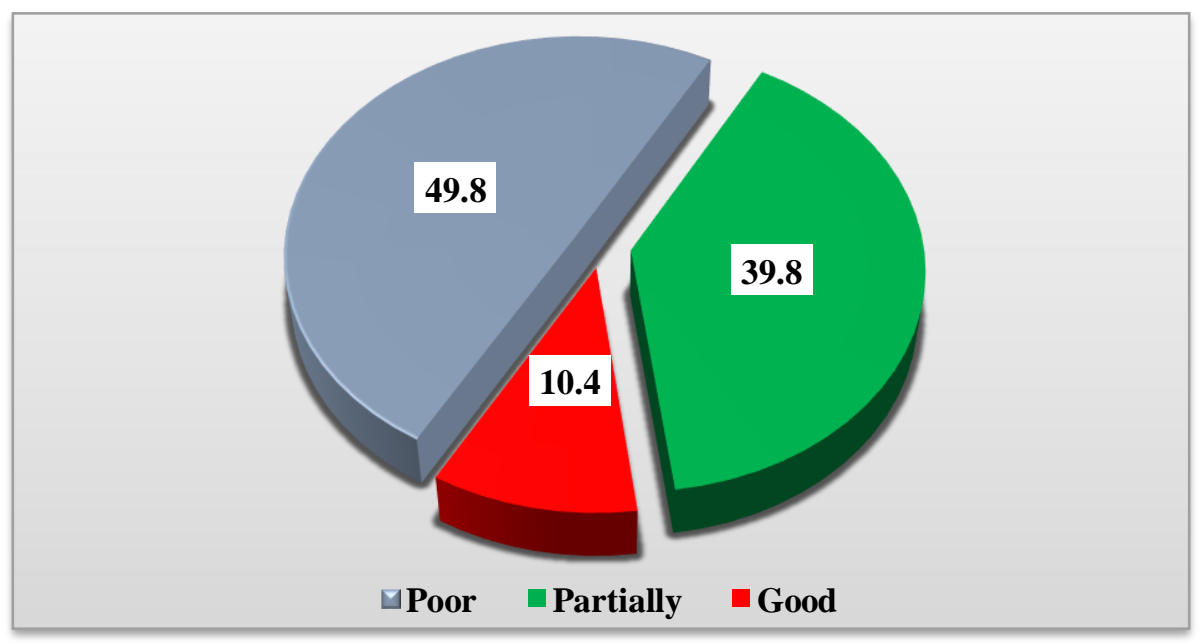

Fig 1. Overall preventive measures towards nosocomial infections.

\subsection{Part III: Relationship Between Preventive Measures of Nosocomial Infections and Demographic Characteristics}

Findings depict there was no significant relationship between health care workers preventive measures towards nosocomial infections and demographic characteristics at p-value $>0.05$ $\left(\chi^{2}\right.$ obs $>\chi^{2}$ cri) except, health workers age and years of experience has been significantly associated at $\mathrm{p}$-value $\leq 0.05$ ( $\left.\chi^{2} \mathrm{obs}<\chi^{2} \mathrm{crit}\right)$. The strong positive association could be because as the number of years of service increases, healthcare workers are repeatedly exposed to infection prevention principles and became more experienced, Table 2 results showed that the status. Our results are consistent with those of a study conducted in Palestinian hospitals, shows a comparison of mean practice scores about socio-demographic characteristics of the studied 
sample. It displays that high mean practice scores were found among those who were in the age group of 20-30 and who attended training courses ${ }^{[24]}$. It is clear that age is an important factor in infection prevention practice, showing that healthcare staff who are over 30 years of age or older have around twice times to application of infection prevention practices appropriately as opposed to those who are less than 30 years of age this may be due to advanced age and long years of service, which over time leads to improvement in their practices, in addition to age, long work experience, and educational status were significantly associated with infection prevention practice ${ }^{[25]}$. The practice of preventing hospital-acquired infection is significantly associated with the educational level and work experience of health care staff at $(\mathrm{p}=0.027$ and 0.044 respectively $)^{[23]}$. Findings from Trinidad and Tobago confirmed that there was no significant association between socio-demographic variables with their practices $(p>0.05)^{[26]}$.

Table 2. The statistical relationship between health care workers' preventive measures and their demographic characteristics.

\begin{tabular}{|c|c|c|c|c|c|c|c|c|}
\hline \multirow{2}{*}{ Variables } & \multirow{2}{*}{ Rating } & \multicolumn{3}{|c|}{ Preventive measures } & \multirow{2}{*}{ Total } & \multirow{2}{*}{ D.f } & \multirow{2}{*}{\multicolumn{2}{|c|}{ Sig. }} \\
\hline & & Poor & Partially & Good & & & & \\
\hline \multirow{6}{*}{ Age } & $<20$ years old & 0 & 5 & 0 & 5 & \multirow{6}{*}{8} & \multirow{6}{*}{$\begin{array}{c}\chi^{2} \text { obs. }=37.912 \\
\chi^{2} \text { crit. }=15.50 \\
\text { P-value }=0.000\end{array}$} & \multirow{6}{*}{ HS } \\
\hline & 20-29years old & 163 & 121 & 32 & 316 & & & \\
\hline & 30-39years old & 54 & 49 & 18 & 121 & & & \\
\hline & 40-49years old & 13 & 24 & 2 & 39 & & & \\
\hline & 50and older & 19 & 0 & 0 & 19 & & & \\
\hline & Total & 249 & 199 & 52 & 500 & & & \\
\hline \multirow{3}{*}{ Gender } & Male & 129 & 101 & 21 & 251 & \multirow{3}{*}{2} & \multirow{3}{*}{$\begin{array}{l}\chi^{2} \text { obs }=2.286 \\
\chi^{2} \text { crit. }=5.991 \\
\text { P-value }=0.319\end{array}$} & \multirow{3}{*}{ NS } \\
\hline & Female & 120 & 98 & 31 & 249 & & & \\
\hline & Total & 249 & 199 & 52 & 500 & & & \\
\hline \multirow{3}{*}{ Residences } & Urban & 239 & 193 & 49 & 481 & \multirow{3}{*}{2} & \multirow{3}{*}{$\begin{array}{l}\chi^{2} \text { obs }=0.919 \\
\chi^{2} \text { crit. }=5.991 \\
\text { P-value }=0.632\end{array}$} & \multirow{3}{*}{ NS } \\
\hline & Rural & 10 & 6 & 3 & 19 & & & \\
\hline & Total & 249 & 199 & 52 & 500 & & & \\
\hline \multirow{6}{*}{ Specialty } & Physician & 27 & 20 & 5 & 52 & \multirow{6}{*}{8} & \multirow{6}{*}{$\begin{array}{c}\chi^{2} \text { obs. }=4.417 \\
\chi^{2} \text { crit. }=15.50 \\
\text { P-value }=0.818\end{array}$} & \multirow{6}{*}{ NS } \\
\hline & Nurse & 75 & 58 & 18 & 151 & & & \\
\hline & $\begin{array}{c}\text { Medical } \\
\text { technologies }\end{array}$ & 47 & 41 & 8 & 96 & & & \\
\hline & $\begin{array}{c}\text { Medical } \\
\text { assistance }\end{array}$ & 89 & 75 & 17 & 181 & & & \\
\hline & Sciences & 11 & 5 & 4 & 20 & & & \\
\hline & Total & 249 & 199 & 52 & 500 & & & \\
\hline \multirow{6}{*}{$\begin{array}{l}\text { Education } \\
\text { attainment }\end{array}$} & Preparatory & 15 & 13 & 2 & 30 & \multirow{6}{*}{8} & \multirow{6}{*}{$\begin{array}{c}\chi^{2} \text { obs. }=3.749 \\
\chi^{2} \text { crit. }=15.50 \\
\text { P-value }=0.879\end{array}$} & \multirow{6}{*}{ NS } \\
\hline & Diploma & 143 & 113 & 28 & 284 & & & \\
\hline & Bachelors & 77 & 63 & 16 & 156 & & & \\
\hline & \begin{tabular}{|l|} 
Higher diploma \\
\end{tabular} & 5 & 4 & 2 & 11 & & & \\
\hline & Master and above & 9 & 6 & 4 & 19 & & & \\
\hline & \begin{tabular}{|c|} 
Total \\
\end{tabular} & 249 & 199 & 52 & 500 & & & \\
\hline \multirow{4}{*}{$\begin{array}{c}\text { Years of } \\
\text { experience }\end{array}$} & <10years & 196 & 132 & 39 & 367 & \multirow{4}{*}{4} & \multirow{4}{*}{$\begin{array}{l}\chi^{2} \text { obs. }=11.10 \\
\chi^{2} \text { crit. }=9.488 \\
\text { P-value }=0.025\end{array}$} & \multirow{4}{*}{$\mathrm{S}$} \\
\hline & 10-20years & 44 & 58 & 13 & 115 & & & \\
\hline & 21-30years & 9 & 9 & 0 & 18 & & & \\
\hline & Total & 249 & 199 & 52 & 500 & & & \\
\hline
\end{tabular}




\begin{tabular}{|c|c|c|c|c|c|c|c|c|}
\hline \multirow{3}{*}{ Work hours } & $\leq 8$ hours & 223 & 170 & 49 & 442 & \multirow{3}{*}{2} & \multirow{3}{*}{$\begin{array}{l}\chi^{2} \text { obs. }=3.765 \\
\chi^{2} \text { crit. }=5.991 \\
\text { P-value }=0.152\end{array}$} & \multirow{3}{*}{ NS } \\
\hline & $>8$ hours & 26 & 29 & 3 & 58 & & & \\
\hline & Total & 249 & 199 & 52 & 500 & & & \\
\hline \multirow{9}{*}{ Workplace } & $\begin{array}{c}\text { Emergency } \\
\text { depart. }\end{array}$ & 25 & 27 & 6 & 58 & \multirow{9}{*}{14} & \multirow{9}{*}{$\begin{array}{c}\chi^{2} \text { obs. }=12.27 \\
\chi^{2} \text { crit. }=23.68 \\
\text { P-value }=0.584\end{array}$} & \multirow{9}{*}{ NS } \\
\hline & $\begin{array}{c}\text { Consulting } \\
\text { depart. }\end{array}$ & 40 & 37 & 7 & 84 & & & \\
\hline & Surgical wards & 23 & 14 & 8 & 45 & & & \\
\hline & Medical wards & 30 & 17 & 6 & 53 & & & \\
\hline & ICU & 15 & 16 & 7 & 38 & & & \\
\hline & Maternity wards & 21 & 18 & 4 & 43 & & & \\
\hline & Pediatric wards & 21 & 12 & 2 & 35 & & & \\
\hline & Laboratories & 74 & 58 & 12 & 144 & & & \\
\hline & Total & 249 & 199 & 52 & 500 & & & \\
\hline \multirow{5}{*}{ Training course } & No training & 76 & 59 & 11 & 146 & \multirow{5}{*}{6} & \multirow{5}{*}{$\begin{array}{c}\chi^{2} \text { obs. }=7.619 \\
\chi^{2} \text { crit. }=12.59 \\
\text { P-value }=0.267\end{array}$} & \multirow{5}{*}{ NS } \\
\hline & One session & 71 & 72 & 18 & 161 & & & \\
\hline & Two sessions & 54 & 38 & 16 & 108 & & & \\
\hline & More than two & 48 & 30 & 7 & 85 & & & \\
\hline & Total & 249 & 199 & 52 & 500 & & & \\
\hline
\end{tabular}

\section{Conclusion}

This study found that with preventive measures concerning nosocomial infections, health care workers were poor preventive measures due to limitation of training and shortage of health resources. More years of experience and more training the staff on infection control programs by local officials help to raise professionals' health workers preventive measures. As well as, Provide the facilities and exploiting young energies of health staff which indeed help to develop their practice.

\section{References}

[1] Shi Y, Wang J, Yang Y, Wang Z, Wang G, Hashimoto K, Zhang K, Liu H. Knowledge and attitudes of medical staff in Chinese psychiatric hospitals regarding COVID-19. Brain, Behavior, \& ImmunityHealth. 2020 Apr 1;4:100064.

[2] Huynh G, Nguyen TN, Vo KN, Pham LA. Knowledge and attitude toward COVID-19 among healthcare workers at District 2 Hospital, Ho Chi Minh City. Asian Pacific Journal of Tropical Medicine. 2020 Jun 1;13(6):260.

[3] Biberaj P, Gega M, Bimi I. Knowledge and source of information among health care students on nosocomial infections. Proceedings of the in Proceedings of the International Journal of Humanities Social Sciences and Education (IJHSSE. 2014 Jul;1:46-51.

[4] Sarani H, Balouchi A, Masinaeinezhad N, Ebrahimitabs E. Knowledge, attitude, and practice of nurses about standard precautions for hospital-acquired infection in teaching hospitals affiliated to Zabol University of Medical Sciences (2014). Global journal of health science. 2016 Mar;8(3):193.

[5] Kretzer D. STANDARD PRECAUTIONS (INCLUDING HAND HYGIENE AND USE OF PPE). Policy. 2018 Jan 18. 
[6] Asmr Y, Beza L, Engida H, Bekelcho T, Tsegaye N, Aschale Y. Assessment of knowledge and practices of standard precaution against blood borne pathogens among doctors and nurses at adult emergency room in Addis Ababa, Ethiopia. Emergency medicine international. 2019 Apr 23;2019.

[7] Buowari OY. Universal Precautions: A Review. Nigerian Health Journal. 2012;12(3):68-74.

[8] Johnson OE, Asuzu MC, Adebiyi A. Knowledge and practice of universal precautions among professionals in public and private health facilities in Uyo, Southern Nigeria-a comparative study. Ibom Med. 2013;5(1):9-19.

[9] Vermeil T, Peters A, Kilpatrick C, Pires D, Allegranzi B, Pittet D. Hand hygiene in hospitals: anatomy of a revolution. Journal of Hospital Infection. 2019 Apr 1;101(4):383-92.

[10] Zakeri H, Ahmadi F, Rafeemanesh E, Saleh LA. The knowledge of hand hygiene among the healthcare workers of two teaching hospitals in Mashhad. Electronic physician. 2017 Aug;9(8):5159.

[11] Saito H, Kilpatrick C, Pittet D. The 2018 World Health Organization SAVE LIVES: clean your hands campaign targets sepsis in health care.

[12] Swan J, McDonald M. Infection Control Training for New York State Healthcare Professionals.

[13] Brown L. Use of personal protective equipment in nursing practice. Nursing Standard. 2019 May $1 ; 34(5)$.

[14] Datta A, Nag K, Karmakar N, Chakraborty T. An epidemiological study on knowledge, attitude and practice of injection safety among health care personnel in a tertiary care hospital of Tripura. International Journal of Community Medicine and Public Health. 2018 Sep;5(9):4128-34.

[15] Yazie TD, Sharew GB, Abebe W. Knowledge, attitude, and practice of healthcare professionals regarding infection prevention at Gondar University referral hospital, northwest Ethiopia: a crosssectional study. BMC research notes. 2019 Dec;12(1):1-7.

[16] Daham, F. H. ASSESSMENT OF OCCUPATIONAL HAZARDS ON HEALTH WORKERS OF TWO HOSPITALS (AL-KUT AND AL-KARAMA) IN WASIT GAVERNORATE. A thesis for partial Fulfillment master Degree/ Southern Technical University.2020,P.37-79.

[17] Mohd-Nor N, Bit-Lian Y. Knowledge, attitude and practices of standard precaution among nurses in middle-east hospital. SciMedicine Journal. 2019 Dec 1;1(4):189-98..

[18] Gawad A. Assessment of knowledge about standard precautions and nosocomial infection among nurses working in hospitals of Sana'a city, Yemen. International Journal of Caring Sciences. 2017 Jan $1 ; 10(1)$.

[19] Okwii M. Knowledge, Attitude And Practices Of Nurses On Prevention And Control Of Hospital Acquired Infections In Soroti Regional Referral Hospital (Doctoral dissertation, International Health Sciences University).

[20] Mohammadzadeh M, Behnaz F, Parsa S. Knowledge, practice and attitude towards standard isolation precautions in nurses, auxiliary nurses and midwives of Shahid Sadoughi Hospital, Yazd, Iran. Int J Infect Control. 2013;9(1):1-8.

[21] Alrubaiee G, Baharom A, Shahar HK, Daud SM, Basaleem HO. Yemeni Nurses' Knowledge and Practices of Nosocomial Infection. Control Measures at Baseline: An Intervention Study. Global Journal of Medical Research. 2018;18(1):1-0.

[22] Maynard, E. Knowledge and Practice of Preventive Measures for Nosocomial Infections among Health Workers in Primary Health Care Center in Aluu , Rivers State, 2019.

[23] Bayleyegn B, Mehari A, Damtie D, Negash M. Knowledge, Attitude and Practice on HospitalAcquired Infection Prevention and Associated Factors Among Healthcare Workers at University of Gondar Comprehensive Specialized Hospital, Northwest Ethiopia. Infection and Drug Resistance. 2021;14:259.

[24] Ayed A. Knowledge and practice of nursing staff towards infection control measures in the Palestinian hospitals.

[25] Desta M, Ayenew T, Sitotaw N, Tegegne N, Dires M, Getie M. Knowledge, practice and associated factors of infection prevention among healthcare workers in Debre Markos referral hospital, Northwest Ethiopia. BMC health services research. 2018 Dec;18(1):1-0.

[26] Unakal CG, Nathaniel A, Keagan B, Alexandria B, Lauralee B, Varun C, Akpaka PE. Assessment of knowledge, attitudes, and practices towards infection prevention among healthcare workers in Trinidad and Tobago. International Journal of Community Medicine and Public Health. 2017 Jul;4(7):2240-7. 